\title{
AUTORES-TRADUTORES NA SÉRIE VAGA-LUME: OS CASOS DE LÚCIA MACHADO DE ALMEIDA E MARCOS REY
}

\author{
TRANSLATING AUTHORS IN THE VAGA-LUME SERIES: THE CASES OF LÚCIA \\ MACHADO DE ALMEIDA AND MARCOS REY
}

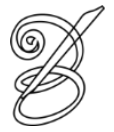

Cynthia Beatrice COSTA*

Universidade Federal de Uberlândia, Brasil

\begin{abstract}
Resumo: O presente artigo tem por objetivo examinar o trabalho dos autores Lúcia Machado de Almeida e Marcos Rey, sobretudo no que diz respeito ao uso de língua estrangeira e a menções a outros países e culturas, em suas narrativas policiais $O$ escaravelho do diabo (1973) e O mistério do cinco estrelas (1981), respectivamente. Ambas são voltadas ao público juvenil e publicadas com notório sucesso comercial na célebre Série Vaga-Lume, da Editora Ática, tradicionalmente adotada nas aulas de literatura nas escolas brasileiras. Além de escritores, Almeida e Rey atuavam também como tradutores de literatura infantojuvenil, tendo publicado traduções de livros e até mesmo de histórias em quadrinhos - no caso de Rey - para jovens leitores nas décadas de 1960 e 1970. Parte-se da hipótese, aqui, de que eles agem como "autotradutores" nessas suas obras da Série Vaga-Lume, ao propor soluções em português brasileiro para termos estrangeiros que eles mesmos utilizam. Trata-se de uma noção de "autotradução" diferente da usual, pois se refere à preocupação de esclarecer no texto termos utilizados pelo próprio autor. Outra hipótese aventada é a de que, ao retratarem uma miríade de personagens estrangeiras e, com elas, seus sotaques e idiomas, os autores operaram uma mediação cultural entre o que vem de fora e o público juvenil brasileiro. Suas narrativas são pontuadas por frequentes referências enaltecedoras a países ditos desenvolvidos, o que pode torná-las reforçadoras, para o jovem leitor, de assimetrias na percepção da ordem internacional (COHEN, 1976), localizando o Brasil e a América Latina como coadjuvantes em um mundo protagonizado pelos Estados Unidos e pela Europa Ocidental. Fontes que abordam o ensino de língua estrangeira no Brasil dos anos 1970 e 1980 (LEFFA, 1999; NICHOLLS, 2001), de modo a avaliar em que contexto escolar esses livros surgiram, e a tese do imperialismo cultural (TOTA, 2000; HARVEY, 2005; SAID, 2011) serviram de apoio para a verificação dessas hipóteses.
\end{abstract}

Palavras-chave: Série Vaga-Lume. Mediação Cultural. Imperialismo Cultural. Lúcia Machado de Almeida. Marcos Rey.

Abstract: The purpose of this paper is to examine the work of the authors Lúcia Machado de Almeida and Marcos Rey, especially in regard to the use of foreign language and to mentions to other countries and cultures, in their narratives $\mathrm{O}$ escaravelho do diabo (1973) and $\mathrm{O}$ mistério do cinco estrelas (1981), respectively. Both are crimerelated and aimed at a young audience; they were published with a notable commercial success in the famous Vaga-Lume series, by Editora Ática, traditionally adopted for literature courses in Brazilian schools. Almeida and Rey were also translators of children's literature, having published translations of books and even comics - in the case of Rey - for young readers in the 1960s and 1970s. The hypothesis explored here is that they act as "selftranslators" in these works, by proposing solutions in Brazilian Portuguese for foreign terms that they themselves use. It is a notion of "self-translation" different from the usual one, since it refers to the concern to clarify in the text terms used by the authors themselves. Another hypothesis presented here is that, by portraying a myriad of foreign characters and their accents and languages, both writers acted as cultural mediators between what comes from abroad and the Brazilian young audience. In addition, their narratives are also punctuated by frequent exalting references to so-called developed countries, which may reinforce asymmetries in the perception of the international order (COHEN, 1976), relegating Brazil and Latin America to supporting roles in a world led by the United States and Western Europe. Studies on foreign language teaching in Brazil in the 1970s and 1980s (LEFFA, 1999; NICHOLLS, 2001), as a means of approaching the context in which the books first appeared, and 
the thesis of cultural imperialism (TOTA, 2000; HARVEY, 2005; SAID, 2011) provided support for the verification of these hypotheses.

Keywords: Vaga-Lume Series. Cultural Mediation. Cultural Imperialism. Lúcia Machado de Almeida. Marcos Rey.

RECEBIDO EM: 21 de fevereiro de 2019

ACEITO EM: 04 de maio de 2019

PUBLICADO EM: julho 2019

\section{Introdução}

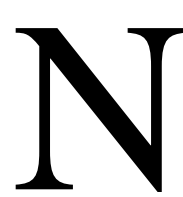

o início da década de 1970, a editora Ática deu início a uma coleção de literatura juvenil comercialmente bem-sucedida, a Série Vaga-Lume. Vários de seus livros continuam em circulação ainda hoje - dentro e fora da série - e são costumeiramente relacionados à nostalgia das gerações nascidas nas décadas de 1970 e 1980. Quando do relançamento de dez de seus títulos em 2015, destacou-se que, além de habitar "o imaginário do brasileiro há mais de quatro décadas" (RODRIGUES, 2015, n.p.), as vendas dos seus (atualmente) cerca de 75 títulos sempre haviam sido expressivas. Acredita-se que alguns de seus livros tenham chegado à marca de três a quatro milhões de exemplares vendidos, o que os torna, no cenário editorial brasileiro, indubitáveis best-sellers (MACHADO, 2012, n.p.).

O surgimento da série coincidiu com a implementação das mudanças propostas pela Lei de Diretrizes e Bases 5.692, de 11 de agosto de 1971, segundo a qual "o $2^{\circ}$ grau passou a ter como principal objetivo a profissionalização" (BELTRÃO, 2017, n.p.). A meta, portanto, era formar o jovem para o mercado de trabalho - o que pode explicar, em conjunto com o "relevo ao estudo da língua nacional, como instrumento de comunicação e como expressão da cultura brasileira" (BRASIL, 1971), uma abertura maior na sala de aula à literatura contemporânea produzida no país. A Série Vaga-Lume, cujos livros são editados pela divisão de paradidáticos da Ática e vendidos com um roteiro de leitura, foi concebida, portanto, para ser lida nas escolas (BORELLI, 1996, p. 107) - no período letivo, inclusive, não nas férias: “Os lançamentos da coleção Vagalume chegavam às livrarias em duas principais datas, fevereiro e agosto, meses em que se reestabelecia a rotina escolar pós-férias" (BUENO, 2016, p. 108).

Entre os seus ilustres autores, figuram a mineira Lúcia Machado de Almeida (19102005), com seis títulos publicados na Série, e o paulistano Marcos Rey (1925-1999), com 15 títulos e a reputação de ter fortalecido a coleção a partir de 1981, quando da publicação de $O$ mistério do cinco estrelas. Ambos colaboraram para a consolidação do gênero policial como um atrativo na Vaga-Lume: "Essa tendência surge ainda com Lúcia Machado de Almeida, mas 
se concretizará em Marcos Rey e suas narrativas policiais, que dão identidade à série" (MENDONÇA, 2007, p. 124).

Em sua primeira leva, em 1973, a Série lançou O escaravelho do diabo, de Almeida, antes já publicado em folhetim na revista carioca O Cruzeiro entre 1952 e 1953. Considerado um clássico da Vaga-Lume, o título foi um dos escolhidos pela Ática para o relançamento de 2015, com projeto gráfico modernizado e nova revisão ortográfica do texto. Foi também adaptado para o cinema pelo diretor Carlo Millani em 2016.

Em 1968, Almeida ganhou o Prêmio Jabuti de literatura juvenil por Xisto no espaço. Rey, por sua vez, foi um autor profícuo de literatura também para adultos. Assim como Almeida, foi agraciado com o Prêmio Jabuti, mas na categoria conto, com $O$ Último Mamífero do Martinelli (1994), além de ter sido membro da Academia Paulista de Letras de 1988 até a sua morte. Ele comentou sobre o seu relacionamento com a Série Vaga-Lume:

Escrevi um policial chamado $O$ mistério do cinco estrelas, que foi um dos cinco livros mais vendidos no país em todos os tempos [...]. E, assim, passei a escrever um livro para essa coleção quase todos os anos. Nestes últimos dezoito anos, de 1980 para cá, escrevi quinze livros. E é claro que fiz isso sem abandonar a literatura para adultos, que, é lógico, nunca me deram (sic) as compensações financeiras que me deram os livros juvenis. (REY, 2004, p. 150).

Está posto, assim, o apelo comercial da Série, mesmo do ponto de vista do escritor, que encontrou nos livros juvenis uma fonte de renda estável que a literatura para adultos não poderia lhe oferecer.

Almeida e Rey foram também tradutores da língua inglesa. Almeida traduziu diversos livros, como o relato de viagem A história de Morro Velho, de Bernard Hollowood, em 1955, e recontou em português clássicos infantis, como Bibi Meia-Longa, de Astrid Lindgren, em 1973. Em início de carreira, Rey traduzia com o irmão, Mário Donato (CUNHA, 2011, p. 7). Quando ainda adotava a grafia Marcos Rei, assinou com ele a tradução de Pato Donald e seus amigos e Pato Donald na escola (1967) e de A história do petróleo (1958), de Maud e Miska Petersham, entre outras obras para crianças.

No presente artigo, optou-se pela análise de $O$ escaravelho do diabo e de $O$ mistério do cinco estrelas por sua relevância no âmbito da Série Vaga-Lume, mas, sobretudo, porque, nessas narrativas, Almeida e Rey agem como "autotradutores" nas próprias obras, adotando termos e, às vezes, frases inteiras em língua estrangeira que aparecem em tradução para o português brasileiro ou no próprio texto, ou em notas de rodapé. Além disso, as duas tramas possuem uma variedade de personagens provenientes de outros países, o que justifica 
considerar os escritores, ainda, como mediadores culturais entre esses lugares e o público juvenil brasileiro.

O texto está dividido em duas partes: na primeira, são abordados o uso de termos em outras línguas nas duas obras e as referências que fazem ao estrangeiro; na segunda, é enfocada a função de Almeida e Rey como mediadores culturais sob o ponto de vista dos conceitos de assimetria nas relações internacionais (COHEN, 1976); de "centro-periferia" dos Estudos da Tradução (EVEN-ZOHAR, 2013); e de imperialismo cultural (TOTA, 2000; HARVEY, 2005; SAID, 2011). São propostas, então, considerações finais.

\section{Presença da língua estrangeira}

Em variados aspectos, $O$ escaravelho do diabo (doravante, Escaravelho) e $O$ mistério do cinco estrelas (doravante, Cinco estrelas) são similares. O primeiro conta a história de uma série de assassinatos de pessoas ruivas em uma pacata cidade do interior de Minas Gerais; o herói Alberto, estudante de medicina, une-se ao Inspetor Pimentel para desvendar quem é o assassino, do qual seu irmão foi a primeira vítima. Entre as outras personagens principais, estão

88 a irlandesa Cora O’Shea, dona da pensão onde mora Verônica, par romântico de Alberto, e a socialite Rachel Saturnino.

Cinco estrelas narra a aventura de Leo, mensageiro de um hotel de luxo na Bela Vista, em São Paulo, que vê um cadáver sob a cama no quarto de um hóspede rico, o Barão. A partir daí, desenrola-se a ação, que envolve injustiças contra Leo, uma polícia desconfiada e uma quadrilha boliviana de tráfico de drogas. Entre as personagens centrais, estão seu amigo e porteiro do hotel, Guima; Ângela, por quem Leo é apaixonado; e seu primo Gino, um intelectual que joga xadrez e fala inglês fluentemente.

Vê-se, assim, como há elementos comuns. À moda de Agatha Christie, as personagens concentram-se em locais mais ou menos circunscritos (a pensão e o hotel), de modo que os principais suspeitos possam ser conhecidos pelo leitor. Alberto e Leo, embora o primeiro seja bem mais maduro que o segundo, são rapazes "certinhos" e espertos. Ambos têm interesses amorosos e sofrem, em algum momento, por isso. As duas narrativas têm variadas personagens oriundas de outros países e a oportunidade, por isso, de ostentar sotaques e frases inteiras em língua estrangeira. O que as diferencia, por outro lado, é o estilo, com a narrativa ligeira e jovial de Rey sensivelmente menos formal do que a de Almeida.

As expressões e frases em língua estrangeira encontradas em abundância nas duas narrativas vêm acompanhadas ou não de traduções. Estas, por sua vez, podem ser explícitas ou 
implícitas e sugeridas pelo próprio autor no corpo do texto ou por ele ou pelo editor em notas de rodapé, como será abordado a seguir. Quando se pode localizar a tradução, considera-se que o autor agiu, ali, como "autotradutor". É importante salientar que se parte, aqui, do princípio de uma "autotradução" diferente daquela de autores que traduziram obras suas inteiras para outras línguas, tal como fizeram Samuel Beckett, Milan Kundera e João Ubaldo Ribeiro, entre outros. Propõe-se uma noção de autotradução, ou “tradução do texto pelo próprio autor" (ANTUNES, 2007, p. 78), mais pontual, considerando-se que o autor opta por utilizar expressões em língua estrangeira, mas se preocupa em deixar claro o sentido dessas expressões para o leitor. Como se verá nos exemplos analisados, esse fenômeno tradutório ocorre nas duas narrativas da Série Vaga-Lume.

Para a presente análise, foram usadas a $15^{\text {a }}$ edição de Escaravelho, de 1989, e a $2^{\text {a }}$ edição de Cinco estrelas, de 1981. Deve-se atentar, primeiramente, a uma peculiaridade em Escaravelho. Na edição de 1989, 19 traduções (Quadro 1) são apresentadas em notas de rodapé ligadas aos seus respectivos termos ou frases por meio de asterisco(s) assim apresentado(s): (*) ou $(* *)$, no caso de haver duas notas na mesma página. As notas, no entanto, não indicam uma autoria, isto é, se são da autora ou do editor. $\mathrm{Na} 28^{\mathrm{a}}$ edição do livro, quando do seu relançamento com novo projeto gráfico em 2015, algumas dessas notas de rodapé foram eliminadas, e as que permaneceram vêm acompanhadas da indicação N.E. (portanto, nota do editor).

Na primeira versão da novela policial publicada em $O$ Cruzeiro, palavras e frases em inglês não vinham acompanhadas de tradução. Entretanto, as diferenças entre esse primeiro texto e o que foi publicado pela Série Vaga-Lume são muitas e, provavelmente, foram realizadas para adequar o texto ao novo público (adolescentes em geral), bem diferente do público-alvo da revista (feminino adulto). Entre as modificações curiosas, estão a origem da personagem Cora O'Shea, que era escocesa, não irlandesa; e do pai de Rachel, que era um judeu chamado Jacob Steinberg (ALMEIDA, 1953, p. 79-80).

Vê-se, no quadro a seguir, que as expressões e frases em língua estrangeira de Escaravelho são ditas principalmente pela irlandesa Cora O’Shea.

Quadro 1 - Passagens em que a língua inglesa usada em Escaravelho é traduzida em notas de rodapé.

\begin{tabular}{|l|l|}
\hline \multicolumn{1}{|c|}{ Palavra ou frase em língua estrangeira } & \multicolumn{1}{c|}{ Notas de rodapé } \\
\hline $\begin{array}{l}\text { (p. 11) } \\
- \text { “One... two... one..." }(*) \text { dizia Cora O’Shea, } \\
\text { levantando e abaixando os braços. }\end{array}$ & $(*)$ Um... dois... um... \\
\hline $\begin{array}{l}\text { (p. } 11) \\
\text { Todo o sacrifício era pouco para afastar aquele } \\
\text { 'middleage fat' }(* *) \text { que a aborrecia tanto. }\end{array}$ & $(* *)$ gordura de meia idade \\
\hline
\end{tabular}




\begin{tabular}{|c|c|}
\hline $\begin{array}{l}\text { (p. 12) } \\
\text { "One apple a day keeps the doctor away" }(*) \text { repetia } \\
\text { sempre Cora. }\end{array}$ & (*) Uma maçã por dia mantém o médico distante. \\
\hline $\begin{array}{l}\text { (p. 25) } \\
\text { - "What?" (*) }\end{array}$ & (*) O quê? \\
\hline $\begin{array}{l}\text { (p. 58) } \\
\text { - "For heaven's sake"! (*) - exclamou Cora O'Shea. }\end{array}$ & (*) Pelo amor de Deus! \\
\hline $\begin{array}{l}\text { (p. 58) } \\
\text { Quando nada, por causa de uma "charming little face" } \\
(* *) \text { com duas covinhas... }\end{array}$ & $(* *)$ lindo rostinho \\
\hline $\begin{array}{l}\text { (p. 71) } \\
- \text { My dear Clarence! }(*)\end{array}$ & (*) Meu querido Clarence. \\
\hline $\begin{array}{l}\text { (p. 72) } \\
\text { (...) ficou conversando comigo até vinte e três horas } \\
\text { "more or less". }(*)\end{array}$ & $(*)$ mais ou menos. \\
\hline $\begin{array}{l}\text { (p. 73) } \\
\text { "Isn't it clear?" (*) }\end{array}$ & (*) Não está claro? \\
\hline $\begin{array}{l}\text { (p. 74) } \\
\text { - "Good afternoon" }(*) \text { - disse ela. }\end{array}$ & (*) Boa tarde. \\
\hline $\begin{array}{l}\text { (p. 74) } \\
\text { - "All right. Bye, Bye". (**) }\end{array}$ & $(* *)$ Muito bem. Adeus. \\
\hline $\begin{array}{l}\text { (p. 81) } \\
\text { - "I don't agree with you..." (*) }\end{array}$ & (*) Não concordo com você. \\
\hline $\begin{array}{l}\text { (p. 83) } \\
\text { - "Take it easy! Take it easy!" (*) }\end{array}$ & (*) Acalme-se, tenha cuidado. \\
\hline $\begin{array}{l}\text { (p. 90) } \\
\text {-"Who is there?" }(*)\end{array}$ & (*) Quem está aí? \\
\hline $\begin{array}{l}\text { (p. 91) } \\
\text { - "None of your business..." }(*)\end{array}$ & (*) Não é da sua conta. \\
\hline $\begin{array}{l}\text { (p. 91) } \\
\text { - "What means that?" }(* *)\end{array}$ & $(* *)$ Que significa isso? \\
\hline $\begin{array}{l}\text { (p. 100) } \\
\text { - "Something queer..." }(*)\end{array}$ & (*) Alguma coisa estranha... \\
\hline $\begin{array}{l}\text { (p. } 100) \\
\text { - "I'll try" }(* *)\end{array}$ & $(* *)$ Vou experimentar. \\
\hline $\begin{array}{l}\text { (p. 124) } \\
\text { - "Too late, my dear, too late..." (*) }\end{array}$ & (*) Muito tarde, meu caro, muito tarde... \\
\hline
\end{tabular}

Fonte: Almeida (1989).

Destas, não pertencem à fala direta de Cora $\mathrm{O}$ 'Shea: a segunda da página 11, “middleage fat", que, embora obviamente seja uma referência à maneira de pensar da irlandesa, está em discurso indireto; as das páginas 90 e 91, que são proferidas por Mr. Gedeon; e a da página 124, que é imaginada por Alberto como uma fala de Cora. Nota-se, desse modo, que as falas em inglês são uma marca da personagem, constituindo um traço para distingui-la.

Nem todas as palavras em inglês de Escaravelho vêm acompanhadas de traduções em notas de rodapé na edição de 1989. Na página 33, o vocábulo boy é usado no sentido de lanterninha ou mensageiro, pois Alberto recebe um bilhete dele no teatro, durante uma ópera (ALMEIDA, 1989, p. 33). Na página 73, Mrs. O’Shea exclama “Impossible!” e, pouco adiante, despede-se do Inspetor Pimentel com "Good bye", sem que haja traduções explícitas. Nestes 
últimos exemplos, pode-se considerar que a tradução se dá de forma indireta, pois, como resposta às falas da irlandesa, o Inspetor Pimentel diz "Possível ou não, peço-lhe que vigie cada um dos seus hóspedes" no primeiro caso e "Passe bem" no segundo - ou seja, o leitor consegue acompanhar os diálogos porque os sentidos estão implícitos. Na página 100, a personagem responde "Yes" sem que haja, novamente, tradução.

Além disso, Escaravelho exibe uma enorme quantidade de nomes próprios em francês, italiano, alemão e latim graças à citação constante de títulos de peças para piano, óperas, livros, tecidos, nomes de objetos e espécies de insetos e plantas. Variados termos aparecem entre aspas, como na passagem: 'Nisso surgiu Cora, com ar assustado, enfiada em um 'peignoir' de 'tweed' verde com pintas brancas" (ALMEIDA, 1989, p. 91).

Um caso de tradução contida no texto em Escaravelho se dá com o título de um livro. Na página 53, descreve o narrador: "Alberto encontrou-o [Padre Afonso] sentado num banco de jardim da casa paroquial, lendo o livro de Johannes Joergensen sobre Francisco de Assis" (ALMEIDA, 1989, p. 53). Três páginas depois, o título da obra em francês é apresentado: “Não imagina que livro maravilhoso é este, continuou o Padre, estendendo para Alberto o volume de Johannes Joergenssen traduzido por Teodor de Wyzeuz 'Saint François D'Assise Sa Vie et son Ouevre"” (ALMEIDA, 1989, p. 55). É interessante notar como houve um cuidado, por parte da autora, de esclarecer o assunto do livro antes de o título aparecer em francês sem uma tradução propriamente dita.

Essas traduções indiretas ou implícitas no texto podem ser entendidas como exemplos de "autotradução" à medida que se nota um ímpeto de usar língua estrangeira e, ao mesmo tempo, a preocupação de torná-la compreensível ao jovem leitor.

Em Cinco estrelas, logo no início, temos a apresentação de Leo como bellboy, termo usado à época, mas que mesmo assim é esclarecido no texto, como se vê a seguir. Um exemplo mais nítido, portanto, de "autotradução" - Rey usa o termo em inglês, mas o traduz em seguida para o português. Aparecem no livro termos em inglês e espanhol, mas os desta segunda língua não são traduzidos implicitamente.

Quadro 2 - Passagens em que as línguas inglesa e espanhola são usadas em Cinco estrelas e suas traduções.

\begin{tabular}{|l|l|}
\hline \multicolumn{1}{|c|}{ Palavra ou frase em língua estrangeira } & \multicolumn{1}{c|}{ Tradução no texto } \\
\hline $\begin{array}{l}\text { (p. 7) } \\
\text { bellboy }\end{array}$ & $\begin{array}{l}\text { (p. 8) } \\
\text { "a trabalhar no Emperor Park Hotel como bellboy, } \\
\text { mensageiro, das 8 às 18 horas [...]" }\end{array}$ \\
\hline $\begin{array}{l}\text { (p. 8) } \\
\text { tropical garden }\end{array}$ & $\begin{array}{l}\text { (p. 8) } \\
\text { "[...] o tropical garden, pequena floresta onde serviam } \\
\text { gelados e sanduíches" }\end{array}$ \\
\hline
\end{tabular}




\begin{tabular}{|l|l|}
\hline (p. 82) & - \\
- Bueno. & - \\
\hline (p. 83) & - \\
- Disse a você que hay una persona da sociedade & \\
metida nesse caso mas não revelou lo nombre. & \\
\hline $\begin{array}{l}\text { (p. 84) } \\
\text { muchacho }\end{array}$ & - \\
\hline
\end{tabular}

Fonte: Rey (1981).

Há ao menos uma dezena de outros termos em língua estrangeira em Cinco estrelas, mas que podemos considerar mais ou menos (dependendo da região do país) inseridos em nossa língua: shopping (REY, 1981, p. 8); blue jeans (REY, 1981, p. 31); living (REY, 1981, p. 94), long-plays (REY, 1981, p. 97); e flashes fotográficos (REY, 1981, p. 122). No contexto da família italiana de Leo, ouve-se "o nono cantar no banheiro "Sappore di Mare"” (REY, 1981, p. 18) e aparecem ainda polpetas (REY, 1981, p. 15) e ciau (REY, 1981, p. 56), com esta grafia.

Nota-se como é muito menor a quantidade de termos estrangeiros quando comparada com a de Escaravelho. Mas, em Cinco estrelas, uma notória valorização do estrangeiro dá-se, sobretudo, no ambiente do hotel Emperor Park, onde Leo trabalha como bellboy/mensageiro. Lá, ele "recebia gorjetas inclusive em dinheiro estrangeiro. Logo conheceu a cor do dólar, da libra, do peso, do franco, da peseta, que trocava por cruzeiros lá mesmo na casa de câmbio do Park" (REY, 1981, p. 8). Também tinha a oportunidade de conhecer "gente importante, preocupada com telefonemas internacionais" (REY, 1981, p. 9), entre as quais o seu chefe: "O telefone tocou, era para o gerente, que atendeu e começou a falar inglês. Como o telefonema parecia importante [...]" (REY, 1981, p. 24).

O contato com pessoas ricas e famosas é descrito como uma chance única, como quando Leo "carregou as malas dum automobilista francês de Fórmula 1, e levou uma garrafa de mineral ao apartamento de um dos reis do petróleo do Oriente Médio, vestido em trajes típicos" (REY, 1981, p. 9). A família de Leo e seu amigo Guima parecem gratos por poderem acessar minimamente o mundo dos ricos por meio do hotel Emperor Park. Diz a mãe: “- Por isso cuidado, filho. Não vá perder esse emprego. Outro assim você não arranja mais” (REY, 1981, p. 14). Ao ser demitido injustamente, Leo entristece-se e declara: “- Mas eu gostava do Park. Era quase como trabalhar no cinema" (REY, 1981, p. 32).

Já seu primo Gino, descrito como um jovem especialmente inteligente, "ganhava algum dinheiro traduzindo livros infantis do inglês" (REY, 1981, p. 48). Aqui, talvez se possa supor a referência a uma atividade exercida pelo próprio autor, mas o mais relevante, à luz da presente discussão, é notar que, novamente, algo admirável (o trabalho do primo inteligente) tem relação 
com a língua inglesa. Mesmo a sua profissão alternativa gira em torno de línguas estrangeiras, pois "Gino costumava dizer que, se algum dia faltassem as traduções dos livros infantis, tentaria viver como telefonista poliglota dum grande hotel" (REY, 1981, p. 50).

Acostumado a ver estrangeiros loiros e altos circulando pelo Emperor Park, Leo assustase ao deparar, fora do hotel, com um estrangeiro diferente. Comenta ele sobre um dos suspeitos envolvidos na quadrilha do Barão: "Mas estrangeiro, com aquela cara de índio? Aí estava a dúvida, pois sempre que se falava de estrangeiros pensava-se em pessoas altas e loiras” (REY, 1981, p. 35). Após a dúvida da polícia entre Peru e Bolívia como o país de origem do homem a que Leo se refere, descobre-se que Ramon Vargas era, enfim, boliviano. Sabendo agora que ele "não era índio”, Leo se espanta mais uma vez, e o primo Gino lhe explica: “- Na Bolívia espanhóis e índios se misturaram muito" (REY, 1981, p. 51).

Mister Sandman, "antigo pseudônimo de um homem de brasileiríssima fisionomia" (REY, 1981, p. 60), e o ex-lutador alemão Hans Fraz Müller são os únicos representantes do submundo retratado na trama não originários de países vizinhos ao Brasil. Latino-americanos são, invariavelmente, relacionados ao crime. Malena Fuentes e Leonel Barrios, envolvidos no rapto de Leo, “devem ser de algum país da América do Sul” (REY, 1981, p. 109). Ramon, por sua vez, "já estivera preso uma vez, implicado em tráfico de tóxicos. O jornal informava ainda que ele morava no Hotel Acapulco, de terceira categoria, na Rua Vitória” (REY, 1981, p. 51).

Enquanto o Emperor Park é lar do chefe milionário da quadrilha, o Barão, seus contatos de menor escalão moram em um hotel "de terceira categoria" cujo nome homenageia uma cidade mexicana. Ao contrário do inglês, língua implicitamente oficial do cinco-estrelas, no Acapulco "tanto da sala quanto do corredor, [Leo] ouviu palavras em castelhano, que parecia ser o idioma oficial do hotel" (REY, 1981, p. 73). A assimetria entre o elo "Emperor Park/inglês/gente importante" e "Acapulco/castelhano/criminosos" é gritante. Leo e Gino, garotos perspicazes que são, estabelecem essas relações em seus discursos como se fossem naturais. Mesmo que imaginem que o destino da droga seja "Nova Iorque e Los Angeles" (REY, 1981, p. 109), o que se salienta é a origem dos bandidos.

O conceito de assimetria é empregado aqui tal como proposto nos anos 1970, à luz da ordem mundial da época, por Benjamin J. Cohen em A questão do imperialismo. Para ele, o imperialismo seria o "tipo de relações internacionais caracterizadas por uma assimetria particular - uma assimetria de dominação e dependência" e resultaria no "exercício real da influência sobre o comportamento" (COHEN, 1976, p. 20). 
Parte das assimetrias expressas em Cinco estrelas parece refletir uma das consequências do americanismo, como se pode inferir a partir do texto de Antonio Pedro Tota:

\begin{abstract}
Durante muito tempo, o americanismo havia forjado uma imagem desabonadora da América Latina. Valorizava-se o homem branco, protestante, sempre mencionado como condutor do progresso na luta contra a vida selvagem, e criava-se uma imagem oposta para os latino-americanos. Segundo essa concepção, ao sul do Rio Grande estava a América dos índios, dos negros, das mulheres e das crianças. (TOTA, 2000, p. 30).
\end{abstract}

Essa oposição entre o civilizado e o selvagem está nas entrelinhas da narrativa de Rey ao retratar pessoas importantes falando inglês no hotel cinco-estrelas, enquanto latinoamericanos revelam-se envolvidos com rapto, tráfico e assassinatos.

Já na narrativa Almeida, não há menção a latino-americanos, e o deslumbre com o que vem de fora mostra-se mais relacionado ao campo profissional, intelectual e artístico. Na pensão de Mrs. O’Shea, moram “Mr. Graz, o velho suíço professor de Francês num colégio de rapazes” (ALMEIDA, 1989, p. 11), que "tinha no quarto grande uma estante cheia de dicionários, gramáticas em francês e inglês e uma coleção completa Larousse” (ALMEIDA, 1989, p. 29), e "Mr. Gedeon, representante de uma firma norte-americana de artigos ortopédicos" (ALMEIDA, 1989, p. 11 e 12), nascido em Cleveland, Ohio (ALMEIDA, 1989, p. 28).

No quarto capítulo, a pensão recebe Mrs. Juell, "uma pianista norueguesa que tinha acabado de dar um concerto na cidade" (ALMEIDA, 1989, p. 18), mas a noite de recital acaba com a morte de Clarence, filho caçula de Mrs. O’Shea. Devido à morte do irmão, Marmaduke, o filho mais velho da irlandesa, que "estava na Inglaterra aperfeiçoando os seus estudos de Química" (ALMEIDA, 1989, p. 11) telefona de Londres anunciando sua vinda no primeiro avião: "Mrs. O’Shea estava alegre com isso, pois amava muito aquele filho que já estava sendo considerado um dos melhores químicos da Inglaterra” (ALMEIDA, 1989, p. 28).

Antes disso, os pais do protagonista Alberto também haviam tido de retornar ao país após a morte do filho Hugo, pois "seu pai era físico de fama mundial e iniciava uma série de viagens de estudo pelo estrangeiro" (ALMEIDA, 1989, p. 10).

Uma das vítimas do assassino em série da trama é "Maria Fernanda, o mais puro 'contralto' dos últimos tempos”, que "ganhara todos os prêmios em vários concursos e passara cinco anos na Itália, aperfeiçoando-se” (ALMEIDA, 1989, p. 30). A cantora de ópera é, portanto, mais uma personagem a deixar o país para se aprimorar no estrangeiro. Ao final da trama, assim como ela e Marmaduke, Alberto é outro que parte para se aperfeiçoar na Europa: 
Desde que terminara os estudos na Faculdade de Medicina, Alberto pensara fazer um curso de aperfeiçoamento nos Estados Unidos ou na Europa. A oportunidade chegara afinal, e ele partira para a França, indo trabalhar com o Doutor Jean Renaud, o mais famoso Cardiologista de Paris. (ALMEIDA, 1989, p. 115).

A ausência de referências de aperfeiçoamento profissional no país pode passar a impressão de que o Brasil seria limitado demais para talentos desse calibre, ou que, para os privilegiados, ir estudar ou trabalhar fora é uma escolha óbvia. Realça-se, desse modo, uma posição periférica do Brasil - emprestando aqui a concepção de "centro e periferia" dos estudos literários de Itamar Even-Zohar (2013, p. 6) - no âmbito da educação.

Outro aspecto curioso diz respeito à promessa, recebida como tentadora por Rachel e Verônica, de serem levadas para o exterior por seus respectivos pretendentes. O namorado de Rachel propõe-lhe uma fuga para Itália: “- Dê o fora no velho e vamos para a Europa, Rachel. Iremos morar na Itália, em Veneza. Que tal uns passeios de gôndola?” (ALMEIDA, 1989, p. 64). Mas o "velho" em questão, Ravic, também planeja levá-la para Europa para que se recupere do ataque malsucedido que sofrera do assassino em série: “- Caso-me com Rachel logo que ela estiver em condições, e levo-a para a Europa” (ALMEIDA, 1989, p. 77). Verônica, interesse amoroso de Alberto, também recebe a proposta de um homem mais velho: "Phillip Gedeon já lhe propusera casamento, prometendo-lhe uma viagem à Califórnia" (ALMEIDA, 1989, p. 84). Destinos internacionais são vistos, assim, como uma espécie de recompensa pós-nupcial.

A viagem ao exterior como consolo e cura repete-se com os pais de Alberto, que não aparecem ao longo do livro porque estão viajando: "Dali a três dias o médico [Alberto] deveria seguir para a Itália, onde iria encontrar seus pais. A morte de Hugo abalara-os muito, e os dois passavam a maior parte do tempo viajando" (ALMEIDA, 1989, p. 123). A Itália é, mais uma vez, exaltada:

\begin{abstract}
Alberto, que fora à Itália por poucos dias, acabou lá ficando dois meses, pois adorava aquele país. Em nenhum outro lugar do mundo encontrara tanta poesia e beleza aliadas a um tal calor humano. Mas, se Roma, Florença e Veneza o fascinavam com suas já decantadas maravilhas, as velhas pequenas cidades o enterneciam. E foi em Siena e Assis que ele teve algumas das mais puras emoções da vida. (ALMEIDA, 1989, p. 125).
\end{abstract}

Seguindo o tom de deslumbre que pode ser percebido ao longo do livro, o desfecho se dá em meio a hipérboles. Em Paris, Alberto é convidado para jantar com o "Professor Kurt von Richter, um dos mais famosos psiquiatras da Europa" (ALMEIDA, 1989, p. 115). É o psiquiatra quem revela o assassino até então misterioso e que, por sua vez, também “chegou a ser 
considerado a maior autoridade na Europa" em entomologia (ALMEIDA, 1989, p. 116). Notase como todos esses dados relacionam o continente europeu - a Europa Ocidental, especificamente - a profissionais de destaque em áreas científicas.

Como uma exceção em meio a tantas conquistas profissionais no exterior, a pianista Verônica é convidada para ser professora de música no Conservatório de Curitiba, onde Alberto enfim a encontra, e os dois se casam.

\section{Almeida e Rey como mediadores culturais}

Nesta seção, é sugerido um debate acerca do papel de Almeida, em Escaravelho, e de Rey, em Cinco estrelas, como mediadores culturais. Embora o papel do tradutor seja com mais frequência relacionado à mediação entre culturas, pode-se argumentar que esses escritores também agem como mediadores, pois citam abundantemente, em suas obras, outras línguas e culturas. Para além disso, podemos considerar as suas narrativas híbridas do ponto de vista linguístico, pois mesclam à língua portuguesa brasileira passagens em idiomas estrangeiros.

Na esfera dos Estudos da Tradução, a estudiosa canadense Annie Brisset argumenta que a "hibridação pela tradução não tem nada de muito espontâneo na escolha de seus componentes culturais" (2006, p. 178), indicando que, quando se opera uma mediação cultural, haverá inevitavelmente uma tendência para um dos dois lados. O mesmo fora reforçado por Edward Said em Cultura e imperialismo, no qual ele lembra que a mediação cultural nunca é neutra, pois não é possível alcançar "um ponto arquimediano" (SAID, 2011, p. 55) entre duas culturas devido à história e ao contexto social em que está inserido o mediador.

Mas que tipo de mediação Almeida e Rey operam por meio de suas escolhas narrativas? “Apresentar” línguas e culturas parece cabível no caso da literatura juvenil, que, com frequência, será o primeiro contato que o leitor terá com determinada nação estrangeira. Contudo, considerando-se novamente a noção de "centro e periferia", o que se vê nos livros da Série Vaga-Lume é um Brasil marcadamente periférico com relação aos Estados Unidos e à Europa. O "centro" do mundo como que nos engole "neste movimento opostamente centrípeto" em que "os fenômenos são arrastados do centro à periferia" (EVEN-ZOHAR, 2013, p. 6). Em seus respectivos livros, Almeida e Rey apresentam esses locais como superiores de diversas maneiras: ao sugerir a importância das línguas faladas por eles; no deslumbramento das personagens com tudo que é oriundo de fora; na relação frequentemente insinuada entre fama/sucesso profissional e esses lugares. 
E, claro, há o uso da língua estrangeira pelos autores. É relevante contextualizar, mais uma vez, o lançamento dos livros após a LDB de 1971, pois o caráter profissionalizante dado ao $2^{\circ}$ grau provocou "uma redução drástica nas horas de ensino de língua estrangeira", conduzindo a um cenário em que "inúmeros alunos, principalmente do supletivo, passaram pelo 1o. e 2o. graus sem nunca terem visto uma língua estrangeira” (LEFFA, 1999, p. 25-26). Sobre isso, Susan Mary Nicholls observa que a mudança foi imposta

[...] sob a égide de um falso nacionalismo que alegava que a escola não deveria se prestar a ser a porta de entrada de mecanismos de impregnação cultural estrangeira e, através dessa influência, contribuir para o aumento da dominação ideológica de sociedades estranhas à brasileira, consagrando, com isso, um colonialismo cultural a serviço de interesses estrangeiros. Predominante na década de 70 , esse pensamento tomava o ensino de línguas estrangeiras como um instrumento das classes favorecidas para manter privilégios, impondo um domínio social, cultural, político e econômico. (NICHOLLS, 2001, p. 16).

Nicholls nota, assim, uma contradição, "uma ideologia que cristaliza a posse do saber apenas por poucos" (NICHOLLS, 2001, p. 17): ao diminuir o ensino da língua estrangeira nas escolas públicas, o governo teria por suposto objetivo valorizar a cultura nacional; no entanto, isso não impediu a elite de continuar a aprender idiomas em cursos livres. Escolas de inglês, por exemplo, já existiam no Brasil desde a década de 1930, com a fundação no Rio de Janeiro da Sociedade Brasileira de Cultura Inglesa, em 1934 (OLIVEIRA, 2007, p. 76).

O conhecimento de outros idiomas consolidou-se, assim, como mais uma barreira entre ricos e pobres no Brasil; além disso, não aprender a língua estrangeira na escola não impedia os jovens de serem bombardeados com a cultura estadunidense por meio do entretenimento e do consumo em geral - pode-se argumentar, inclusive, que não saber inglês só os tornava mais suscetíveis a isso. Assim como Leo, protagonista de Cinco estrelas, o adolescente brasileiro vestia blue jeans e bebia Coca-Cola.

Podemos refletir sobre esses exemplos como reproduções e reforços, na literatura juvenil, do imperialismo cultural exercido na realidade:

O imperialismo cultural tornou-se importante arma na luta para afirmar a hegemonia geral. Hollywood, a música popular, formas culturais e até movimentos, como o dos direitos civis, forma mobilizados para promover o desejo de emular o modo americano de ser. Os Estados Unidos foram concebidos como um farol de liberdade dotado do poder exclusivo de engajar o resto do mundo numa civilização duradoura caracterizada pela prosperidade. (HARVEY, 2005, p. 53). 
Percebe-se essa hegemonia muito claramente no estilo de vida dos jovens criados por Rey no início dos anos 1980. Como já foi mencionado, ser mensageiro do cinco-estrelas era para Leo como trabalhar no cinema - quer dizer, em Hollywood. Ele assiste, além disso, a horas de TV "enlatada" e ouve long-plays com a namorada. São expressões do American way of life nem sempre percebidas como tal, justamente devido à nossa "fraqueza": "As nações contemporâneas da Ásia, América Latina e África são politicamente independentes, mas, sob muitos aspectos, continuam tão dominadas e dependentes quanto o eram na época em que viviam governadas diretamente pelas potências europeias" (SAID, 2011, p. 40). No contexto da discussão a respeito do imperialismo cultural exercido pelos meios de comunicação, Said ainda diz que

a expansão desenfreada das várias formas de controle cultural originadas dos Estados Unidos criou um novo mecanismo de incorporação e dependência cujo objetivo é subordinar e se impor não só a um público americano interno, mas também a culturas menores e mais fracas. (SAID, 2011, p. 346).

Estávamos, desde a Segunda Guerra e mais fortemente a partir dos anos 1960, em uma “condição de colônia cultural dos Estados Unidos" (ALVES, 1989, p. 7). No período do governo militar, houve um "alinhamento automático aos USA" (ALVES, 1989, p. 48) que se propagava nos nomes das marcas, nas programações musicais das rádios, nos filmes, na TV e no nosso vocabulário habitual. Assim, fora da escola, o jovem brasileiro típico tinha contato exacerbado com a língua estrangeira - só não o tinha de forma educativa e sistemática.

Podemos depreender disso que, ao usarem outras línguas em suas narrativas, Almeida e Rey não imaginavam que o leitor necessariamente as compreenderia - por isso mesmo, eles as traduzem para o português brasileiro no próprio texto ou, ao menos, clarificam o sentido pelo contexto. Neste ponto, é relevante lembrar que a Editora Ática, muito provavelmente, possuía poder de decisão sobre determinadas estratégias narrativas, como o uso de notas de rodapé com esclarecimentos tradutórios em Escaravelho.

Como mediadores culturais, Almeida e Rey pendem não à cultura na qual estão produzindo a obra, mas a culturas outras; a um "outro" que eles mesmos trouxeram, voluntariamente, para a narrativa - esta constituindo uma diferença com relação à tradução, na qual o "outro" é um fato dado, e domesticá-lo ou não, e em que medida, é a questão central da mediação. 


\section{Considerações finais}

Em Escaravelho e Cinco estrelas, é nítida a hipervalorização do estrangeiro - leia-se, aqui, europeu ou estadunidense. Na obra de Almeida, não há referência a países não-europeus além dos Estados Unidos e do próprio Brasil; na de Rey, a quadrilha de "tráfico de tóxicos" envolvida no crime-tema da narrativa é boliviana, o que só corrobora a assimetria.

Embora o presente trabalho não tenha tido por objetivo abordar a recepção dessas obras, talvez seja possível inferir que, no contexto da literatura juvenil e, especificamente, da lucrativa Série Vaga-Lume, uma mensagem de deslumbramento com tudo que vem do chamado "primeiro mundo" pode estar sendo passada de geração em geração sem que os jovens a percebam com clareza; apesar de todos os estudos sociológicos acerca do imperialismo cultural disseminados nas últimas décadas, os livros da coleção continuam a ser publicados e vendidos sem, aparentemente, causar reações relevantes com relação a isso.

Até que ponto as narrativas de Almeida e Rey foram "moldadas" pelos parâmetros da Série, é difícil mensurar. Evidentemente, deve-se ressaltar, por fim, que o problema não está em retratar a juventude com as influências estrangeiras que ela recebe, como os autores o fizeram, mas sim na leitura acrítica dessas influências.

\section{REFERÊNCIAS BIBLIOGRÁFICAS}

ALMEIDA, Lúcia Machado de Almeida. O escaravelho do diabo. 15. ed. São Paulo: Ática, 1989.

ALMEIDA, Lúcia Machado de Almeida. O escaravelho do diabo. 28. ed. São Paulo: Ática, 2015.

ALMEIDA, Lúcia Machado de Almeida. O escaravelho do diabo. O Cruzeiro, Rio de Janeiro, n. 40, p. 79-80, 1953.

ALVES, Júlia Falivene. A invasão cultural norte-americana. São Paulo: Moderna, 1989.

ANTUNES, Maria Alice G. Autotradução e autotradutores: breve histórico. Tradução e Comunicação, v. 16, p. 78-83, 2007.

BELTRÃO, Tatiana. Reforma tornou ensino profissional obrigatório em 1971. Senado Notícias, 3 mar. 2017. Disponível em:

https://www12.senado.leg.br/noticias/materias/2017/03/03/reforma-do-ensino-mediofracassou-na-ditadura Acesso em: 19 fev. 2019.

BORELLI, Sílvia Helena Simões. Ação, suspense, emoção: literatura e cultura de massa no Brasil. São Paulo: Educ/Estação Liberdade, 1996. 
BRASIL. Lei $\mathrm{n}^{\circ}$ 5.692, de 11 de agosto de 1971. Fixa Diretrizes e Bases para o ensino de $1^{\circ} \mathrm{e}$ $2^{\circ}$ graus, e dá outras providências. Diário Oficial da União, seção 1, Brasília, DF, 12 ago.

1971. Disponível em: http://www2.camara.leg.br/legin/fed/lei/1970-1979/lei-5692-11-agosto1971-357752-publicacaooriginal-1-pl.html Acesso em: 19 fev. 2019.

BRISSET, Annie. A tradução: modelo de hibridação das culturas? Interfaces Brasil/Canadá, Rio Grande, n. 6, p. 175-197, 2006. Disponível em:

https://periodicos.ufpel.edu.br/ojs2/index.php/interfaces/article/view/6924 Acesso em: 2 abr. 2019.

BUENO, Zuleika de Paula. Leia o livro, veja o filme, compre o disco: a formação do cinema juvenil brasileiro. Maringá: Eduem, 2016.

COHEN, Benjamin J. A questão do imperialismo: economia política de dominação e dependência. Traduzido por: Maria Isabel da Silva Lopes. Rio de Janeiro: Jorge Zahar, 1976. Tradução de: The question of imperialism: the political economy of dominance and dependence.

CUNHA, Antonieta. Marcos Rey: quando rir é o melhor remédio. In: REY, Marcos. Marcos Rey: crônicas para jovens. São Paulo: Global Editora, 2011. p. 5-9.

EVEN-ZOHAR, Itamar. Teoria dos Polissistemas. Traduzido por: Luis Fernando Marozo; 100 Carlos Rizzon; Karlla Cunha Yanna. Revista Translatio 4, 2013, p. 1-2. Tradução de: Polysystem Theory.

HARVEY, David. O novo imperialismo. Traduzido por: Adail Sobral, Maria Stela Gonçalves. São Paulo: Edições Loyola, 2005. Tradução de: The new imperialism.

LEFFA, Vilson J. O ensino de línguas estrangeiras no contexto nacional. Contexturas, APLIESP, n. 4, 1999.

MACHADO, Cassiano Elek. O misterioso caso do Vaga-Lume. Folha de S. Paulo, ano 92, n. 30.587, 30 dez. 2012. Disponível em: https://www1.folha.uol.com.br/fsp/ilustrada/86205-omisterioso-caso-do-vaga-lume.shtml Acesso em: 19 fev. 2019.

MENDONÇA, Catia Toledo. À sombra da Vaga-Lume: análise e recepção da Série VagaLume. 2007. 305 f. Tese (Doutorado em Letras) - Universidade Federal do Paraná, Curitiba, 2007. Disponível em:

https://acervodigital.ufpr.br/bitstream/handle/1884/13438/Mic?sequence=1 Acesso em: jun. 2019.

NICHOLLS, Susan Mary. Aspectos pedagógicos e metodológicos do ensino de inglês. Maceió: EdUFAL, 2001.

OLIVEIRA, Elisa Pinto de. A relevância de se ensinar/aprender a língua inglesa na escola pública: o discurso de pais e alunos. 2007. 128 f. Dissertação (Mestrado em Estudos Linguísticos e Literários em Inglês) - Faculdade de Filosofia, Letras e Ciências Humanas, USP, São Paulo, 2007. Disponível em: https://www.teses.usp.br/teses/disponiveis/8/8147/tde22102007-115235/pt-br.php Acesso em: jun. 2019. 
REY, Marcos. Marcos Rey. In: MATTOS, David José Lessa (org.). Pioneiros do rádio e da TV no Brasil. São Paulo: Códex, 2004. p. 137-156

REY, Marcos. O mistério do cinco estrelas. 2. ed. São Paulo: Editora Ática, 1981.

RODRIGUES, Maria Fernanda. 'Coleção Vaga-Lume', que revolucionou a literatura juvenil, está de cara nova. O Estado de S. Paulo, 26 set. 2015. Disponível em:

https://cultura.estadao.com.br/noticias/literatura,colecao-vaga-lume--que-revolucionou-aliteratura-juvenil--esta-de-cara-nova,1769263 Acesso em: 19 fev. 2019.

SAID, Edward W. Cultura e imperialismo (edição de bolso). Traduzido por: Denise Bottmann. São Paulo: Companhia das Letras, 2011. Tradução de: Culture and Imperialism (Pocket).

TOTA, Antonio Pedro. O imperialismo sedutor: a americanização do Brasil na época da Segunda Guerra. São Paulo: Companhia das Letras, 2000.

\footnotetext{
* Cynthia Beatrice COSTA - Doutora em Estudos da Tradução (2016) pela Universidade Federal de Santa Catarina, com período sanduíche na Universidade de Yale. Mestre em Literatura e Crítica Literária (2008) pela Pontifícia Universidade Católica de São Paulo. Bacharel em Jornalismo (2002) pela Faculdade Cásper Líbero. Professora adjunta da Universidade Federal de Uberlândia. Uberlândia, Minas Gerais, Brasil.

Currículo acadêmico: http://lattes.cnpq.br/4559061442633545

ORCID: https://orcid.org/0000-0002-3063-0121

E-mail: cynthia_costa@uol.com.br
} 